UCRL-WD-124563

\title{
LLNL Small-Scale Friction Sensitivity (BAM) Test
}

\author{
L. Richard Simpson \\ M. Frances Foltz
}

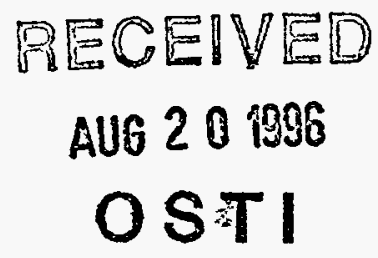

June 1996

This is an informal report intended primarily for internal or limited external distribution. The opinions and conclusions stated are those of the author and may or may not be those of the Laboratory.

Work performed under the auspices of the U.S. Department of Energy by the Lawrence Livermore National Laboratory under Contract W-7405-Eng-48. 


\section{DISCLAIMER}

This document was prepared as an account of work sponsored by an agency of the United States Government. Neither the United States Government nor the University of California nor any of their employees, makes any warranty, express or implied, or assumes any legal liability or responsibility for the accuracy, completeness, or usefulness of any information, apparatus, product, or process disclosed, or represents that its use would not infringe privately owned rights. Reference herein to any specific commercial product, process, or service by trade name, trademark, manufacturer, or otherwise, does not necessarily constitute or imply its endorsement, recommendation, or favoring by the United States Government or the University of California. The views and opinions of authors expressed herein do not necessarily state or reflect those of the United States Government or the University of California, and shall not be used for advertising or product endorsement purposes.

This report has been reproduced directly from the best available copy.

Available to DOE and DOE contractors from the Office of Scientific and Technical Information P.O. Box 62, Oak Ridge, IN 37831

Prices available from (615) 576-8401, FIS 626-8401

Available to the public from the .

National Technical Information Service

U.S. Department of Commerce

5285 Port Royal Rd.

Springfield, VA 22161 


\section{DISCLAIMER}

Portions of this document may be illegible in electronic image products. Images are produced from the best available original document. 


\title{
LLNL Small-Scale \\ Friction Sensitivity (BAM) Test
}

\author{
L. Richard Simpson, and M. Frances Foltz

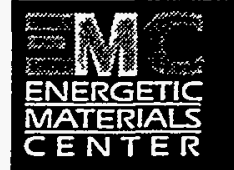 \\ Lawrence Livermore National Laboratory \\ P.O. Box 808, L-281 \\ Livermore, CA 94550
}

\begin{abstract}
Small-scale safety testing of explosives, propellants and other energetic materials, is done to determine their sensitivity to various stimuli including friction, static spark, and impact. Testing is done to discover potential handling problems for either newly synthesized materials of unknown behavior, or materials that have been stored for long periods of time. This report describes the existing "BAM" Small-Scale Friction Test, and the methods used to determine the friction sensitivity pertinent to handling energetic materials. The accumulated data for the materials tested is not listed here - that information is in a database. Included is, however, a short list of 1) materials that had an unusual response, and 2). a few "standard" materials representing the range of typical responses usually seen.
\end{abstract}




\section{Introduction}

The Friction Sensitivity Machine or BAM Machine was developed by the German Bundesanstalt für Materialprufung or BAM, to test friction sensitivity of military explosives. We have adopted it as a standard test for friction sensitivity of explosives at the Lawrence Livermore National Laboratory (LLNL). This is an updated description of the test previously described in an informal report. ${ }^{1}$

\section{Apparatus}

The BAM machine used by LLNL is built by the Julius Peters Company in Berlin, Germany. ${ }^{2}$ There are two machines available from the company: a large machine for testing secondary explosives and a smaller one for testing materials with a high sensitivity to friction (primary explosives). LLNL uses the large machine because only secondary high explosives are tested for handling safety here.

The large friction machine (Figures 1 and 2) consists of a gray cast iron base plate to which a moving porcêlain plate is mounted. A fixed porcelain pin is positioned perpendicular to and just touching the plate. The porcelain plate is held in a clamp on a slide riding on ball bearing rollers in two guide grooves. This slide is driven by a connecting rod, eccentric sheave and geared electric motor, which allows the porcelain plate to go through a reciprocating motion under the porcelain pin. The motor is set up to allow only one rotation of the eccentric when the actuating button is pushed; thereby allowing only one 10$\mathrm{mm}$ stroke of the slide. A collet chuck holding the porcelain pin is mounted to a horizontal arm which can lift to allow replacement of the pin. The arm has six notches for hanging on weights. A counterweight is mounted to compensate for the zero position. Nine different load weights can be hung by a holding ring with a hook, in the corresponding notches (Table I). This allows the load on the porcelain pin to be varied from $0.5 \mathrm{~kg}$ up to $36 \mathrm{~kg}$. The final relative measure of sensitivity is recorded as the smallest load $(\mathrm{kg})$ at which reaction occurred for a 1-in-10 series of attempts. The lower the load values, the higher the friction sensitivity. 


\section{Porcelain Plates and Pins}

The samples are placed on white technical porcelain plates $(25 \times 25 \times 5$ $\mathrm{mm}$ ) and are available only from the vendor. The friction surfaces of the plates are roughened during manufacture by wiping with a sponge prior to kiln firing. This produces striations or "sponge mark" clearly visible on the surface. The pins, also made of white technical porcelain, are cylindrical in shape $(15 \mathrm{~mm}$ long, $10 \mathrm{~mm}$ dia.) and have rounded ends with a spherical radius of $10 \mathrm{~mm}$.

The surfaces of the plate and pin are damaged during use, and only one test can be done on each area. Therefore, the two ends of the pins will allow two tests for each pin, while the surfaces of a plate are large enough to permit 510 tests per side.

\section{Pretest Procedure}

No attempt is made to condition the explosives unless they are known to be unusually hygroscopic. Storage in the test lab for an hour or so is considered acceptable for most explosives. Samples known to be hygroscopic are kept in a desiccator until needed. Ambient temperature is controlled to $68 \pm 3^{\circ} \mathrm{F}\left(19^{\circ} \mathrm{C}\right)$ and humidity varies from 10 to $\sim 80$ percent. Both temperature and humidity at the time of test are recorded.

\section{Procedure}

See Appendix A for a detailed step-by-step procedure. At the beginning of a test, a porcelain plate is placed into the clamp on the slide and secured. The plate is adjusted so that the sponge marks on the plate are oriented perpendicular to the travel of the slide. A pin is inserted into the collet chuck on the arm and the chuck is tightened. A knob on the electric motor shaft allows the motor to be turned by hand so that a mark on the slide can be aligned with the left mark on the base. A small sample of the material to be tested (a few milligrams) is placed on the plate under the pin and the pin is gently lowered onto the sample (Figure 3 ).

In response to apparently anomalous friction values with aluminized $\mathrm{HE}$ formulations and.TATB samples, the procedure was reviewed. The tests listed in the UNO book Recommendations on the Transport of Dangerous Goods are 
required to determine the shipping classification of HE's. ${ }^{3}$ After this review in April 1995, changes were made to bring this procedure into agreement with those in the UNO book. Test data starting with April 7, 1995 reflect this change. The sample size is now standardized by measuring with a cylindrical volumetric measure (2.3 mm dia. $\times 2.4 \mathrm{~mm}$ ) instead of a spatula (pre-April 1995 test data). There was a redesignation of smoking, odor, scorch marks, and reactions other than explosion, sparking, or popping noises from "Go" to "No Go". These observations are recorded in the notebok and are made available should the requester ask for it. The $\mathrm{NO}_{\mathrm{x}}$ tester was discontinued as redundant and a nonstandard criterion.

A weight is chosen according to an index provided by the manufacturer that relates a given weight with the resultant load (in $\mathrm{kg}$ ) on the sample (see Table I). The weight is hung on the arm at the corresponding notch. According to the index, the next higher or lower load may require a change in weight and/or in position on the arm. The starting weight is estimated based on handling experience with similar materials. If it is a new or unfamiliar type of material, the maximum weight of $36 \mathrm{~kg}$ is the starting point. The friction machine is turned on and the room lights are turned off. The actuating button on the machine is pushed and the sample is observed for any reaction. A revision of procedure redesignated smoking, odor and scorch marks and reactions other than explosion, sparking or popping noises from a "Go" (reaction) to a "No Go" (no reaction). This change was done because some materials such as aluminized mixes may leave dark smudges that are not the result of reaction. Other materials like 1,3,5-triamino-2,4,6-trinitrobenzene (TATB) can leave slight smudges that may be due to non-thermal reactions such as stress ${ }^{4}$ and light induced ${ }^{5}$ discoloration. These observations are recorded in the workbook and are available should the requester want this information. The room lights are turned back on. The weight is removed from the arm and the arm is lifted. Observations are recorded in the Friction Machine work book, along with temperature and humidity. The plate is loosened in the clamp and moved sideways slightly to allow a fresh surface for the next test. The collet chuck on the arm is loosened and the pin turned end-for-end. If both ends of the pin have been used, the pin is replaced. The testing is repeated until a one-in-ten reaction is obtained. The weight is decreased if two reactions occur before all ten are tested, and the testing sequence is started again for ten samples at the 
new weight. The only time zero-in-ten is reported is if no reaction has occurred with the heaviest weight, the highest load the machine can deliver.

\section{Data Interpretation and Evaluation}

The sensitivity of an explosive is inverse to the weight applied to cause a reaction: the lower the weight needed, the higher the sensitivity to friction. A "Go" is considered any reaction that can be seen, heard or smelled. Examples are explosions, sparks, pops and flashes. A lack of reaction, or "No Go", is smoking, odor, scorch marks and reactions other than explosion, sparking or popping noises.

Some types of explosives may give apparently anomalous behavior not predicted from other small-scale testing data. Other materials are not candidates for BAM testing because of their intrinsic bulk properties. Paste explosives with a very thin consistency and liquid explosives are not tested on the friction machine at LLNL because their lubricating qualities make testing them meaningless. Paste and liquid explosives are generally not sensitive to friction because of their lubricating qualities. However, a failure to react should not be taken as an indication of their safety.

Examples of materials and their-load values, that yielded unexpected results are listed in Table II. Many of these materials had some amount of metal mixed into the formulation. Also included in Table III are the typical responses of other standard materials.

The BAM procedure suggests a method involving testing until a one-insix reaction is obtained. However, we have been using a one-in-ten reaction because 1) we feel a more stringent reaction criterion is warranted, 2) it is consistent with the rest of LLNL's small-scale safety testing, and 3) because it has been found to be more consistent than the 1 -in- 6 test. It also reveals the lowest sensitivity of the material in question.

Test results using this machine are heavily dependent on the visual and auditory acuity of the operator. Therefore, the results of the test may vary considerably from operator to operator. Consequently, test results can only be relied upon to give a relative ranking of sensitivity between explosives, and a qualitative measure of handling safety. 


\section{Appendix A - Specific Procedure}

1. Turn on machine. The switch is on the front of the machine.

2. Clamp ceramic plate on the slide with the striations at right angle to slide travel (note 1).

3. Clamp ceramic pin in collet chuck on arm.

4. Turn knob on top of motor until white marks on the front of the table are aligned (left side). If marks are not aligned before the test the table will not make a complete stroke.

5. Place a small amount of explosive on the plate under the pin and gently lower the pin onto the sample. Samples are usually powders. Use the cylindrical volumetric measure $(2.3 \mathrm{~mm}$ dia. $\times 2.4 \mathrm{~mm})$ dedicated for this test procedure $(\sim 5 \mathrm{mg})$.

6. Hang the desired weight on the arm at the appropriate position for the desired load on the sample. Starting load (weight) is based upon experience with similar materials. If testing an unknown material, start with the maximum weight (36 kg).

7. Turn off the room lights. Push large red button on the front of the machine. The table will make one back-and-forth motion.

8. Observe and listen for any reactions. A lack of reaction, or "No Go"; is smoking, odor, scorch marks and reactions other than explosion, sparking or popping noises. A reaction ("Go") will include explosions, sparks, pops and flashes (note 2).

9. Turn on room lights. Remove weight from arm and lift arm from sample and look for any marks on the plate. Record any observations. Notations in the workbook are made as follows (note 3):

$$
\begin{aligned}
& \mathrm{O}=\text { No Go; } \\
& \mathrm{X}=\text { Go (explosion, spark, popping noise); } \\
& \mathrm{S}=\text { No Go (smoke, odor, scorch mark). }
\end{aligned}
$$

10. Move the ceramic plate over a little in the clamp on the table to allow reuse for the next test. As many as ten tests can be done on one side of the plate. Both sides of the plates can be used.

11. Remove ceramic pin from collet chuck on the arm and turn it end-forend. Reinsert in collet. If both ends have been used, replace pin.

12. If testing results in 2 reactions before 10 tests are completed, the load must be reduced to the next lower load. Start counting from the beginning of the 
10-test sequence with the new weight. The new weight corresponds to the next lowest load as found with the table provided with the machine (see Table I). Change weights as often as the 2 -in-10 reactions occur, until the minium weight is reached.

13. Continue with steps 5 through 12 until test is concluded.

14. The test as conducted at LLNL requires a $1-$ in-10 reaction at the - lowest possible loading. The final relative measure of friction sensitivity is therefore recorded as the smallest pin load (in $\mathrm{kg}$ ) at which reaction occurred once in ten attempts.

\section{Notes:}

1) When used in the past, the NOx meter would now be turned on and the meter zeroed before use.

2) Historically, when a $\mathrm{NO}_{x}$ meter was used, a reading of $25 \mathrm{ppm}$ or higher was recorded as a reaction.

3) Historical notations in the workbooks for the $\mathrm{NO}_{\mathrm{x}}$ meter were recorded as $\mathrm{O}=0$-24 ppm ("No Go"); X=25-50 ppm ("Go"). 


\section{References}

1. G.L. Moody, "Hazard Characterization of Explosives by Use of the Friction Sensitivity Test," Informal Report UCID-21052, Lawrence Livermore National Laboratory, Livermore, CA ( March 1987).

2. Dr. Held and Dr. Wachtler, "Studie über Auswerteverfahren für die Reivempfindlichkeit nach BAM", MBP Report SOB-620, Messerschmitt-BoklowBlohm GMBH, Germany (March 30, 1978)

3. Recommendations on the Transport of Dangerous Goods, Tests and Criteria, 2nd ed.; Labelmaster: Chicago, 1990.

4. M. W. Miles, D. Gustaveson, K. L. Devries, "Stress-Induced Radical Generation in TATB", J. Mat. Sci. 18, 3243-3248 (1983).

5. A. D. Britt, et al., "Free Radicales of TATB", Propellants and Explosives 6, 94-95 (1981). 
Table I

Load in Kilograms $(\mathrm{kg})$

\begin{tabular}{|c|c|c|c|c|c|c|}
\hline & \multicolumn{7}{|c|}{ Notch Number } \\
\hline Weight & $\mathrm{I}$ & $\mathrm{II}$ & $\mathrm{III}$ & $\mathrm{IV}$ & $\mathrm{V}$ & $\mathrm{VI}$ \\
\hline 1 & 0.5 & 0.6 & 0.7 & 0.8 & 0.9 & 1.0 \\
\hline 2 & 1.0 & 1.2 & 1.4 & 1.6 & 1.8 & 2.0 \\
\hline 3 & 2.0 & 2.4 & 2.8 & 3.2 & 3.6 & 4.0 \\
\hline 4 & 3.0 & 3.6 & 4.2 & 4.8 & 5.4 & 6.0 \\
\hline 5 & 4.0 & 4.8 & 5.6 & 6.4 & 7.2 & 8.0 \\
\hline 6 & 6.0 & 7.2 & 8.4 & 9.6 & 10.8 & 12.0 \\
\hline 7 & 8.0 & 9.6 & 11.2 & 12.8 & 14.4 & 16.0 \\
\hline 8 & 12.0 & 14.4 & 16.8 & 19.2 & 21.6 & 24.0 \\
\hline 9 & 18.0 & 21.6 & 25.2 & 28.3 & 32.4 & 36.0 \\
\hline
\end{tabular}


Table II

\begin{tabular}{|l|l|l|}
\hline \multicolumn{3}{|c|}{ Unusual Responses or Materials } \\
\hline material * & reaction & test date \\
\hline Diaminopropane Diperchlorate & $\begin{array}{l}\text { Big "pop" @ } \geq 3.6 \mathrm{~kg} \text { (broke } \\
\text { ceramic plate) }\end{array}$ & $7 / 22 / 87$ \\
\hline FEFO (neat liquid) & Flame but no sound, 1/10 @ 9.6 & $9 / 7 / 82$ \\
\hline $\mathrm{K}-6$ (early batch) & Big "pop" @ $\geq 9.6 \mathrm{~kg}$ & $9 / 10 / 87$ \\
\hline $\begin{array}{l}\text { Silver Nitrocyanamide } \\
\left(\mathrm{AgCN} \mathrm{O}_{2}\right)\end{array}$ & $1 / 10 @ 1.8 \mathrm{~kg}$ & $1 / 31 / 80$ \\
\hline Table Sugar (granulated) & $1 / 10 @ 24 \mathrm{~kg}$ & $11 / 10 / 94$ \\
\hline TAG-ETNA & $\begin{array}{l}\text { Violent report - shattered plate \& } \\
\text { anvil both runs - 2/2 @ 0.5 kg }\end{array}$ & $3 / 26 / 82$ \\
\hline $\begin{array}{l}\mathrm{ZrH} / 2 / \mathrm{Al} / \mathrm{KP} / \mathrm{HMX} \\
(38 / 39 / 20 / 3 \text { wt \%) }\end{array}$ & Big "pop" and sparks @ $\geq 7.2 \mathrm{~kg}$ & $3 / 16 / 88$ \\
\hline
\end{tabular}


Table III

\begin{tabular}{|c|c|c|}
\hline \multicolumn{3}{|c|}{ Standard Material Responses } \\
\hline material * & reaction & test date \\
\hline AHH propellant & $1 / 10 @ 10.8 \mathrm{~kg}$ & $10 / 2 / 91$ \\
\hline ANFO & $0 / 10 @ 36.0 \mathrm{~kg}$ & $1 / 15 / 93$ \\
\hline ANTA & $1 / 10 @ 19.2 \mathrm{~kg}$ & $10 / 15 / 92$ \\
\hline Black Powder & $0 / 10 @ 36 \mathrm{~kg}$ & 1/15/93 \\
\hline $\mathrm{CL}-14$ & $1 / 10 @ 19.2 \mathrm{~kg}$ & $2 / 14 / 92$ \\
\hline CL-20 (epsilon) & $1 / 10 @ 6.4 \mathrm{~kg}$ & $7 / 12 / 90$ \\
\hline Comp B-3 & $1 / 10 @ 4.8 \mathrm{~kg}$ & $10 / 22 / 91$ \\
\hline 2,4-DNI & $1 / 10 @ 12.4 \mathrm{~kg}$ & $10 / 14 / 92$ \\
\hline HMX (grade II) & $1 / 10 @ 11.6 \mathrm{~kg}$ & $7 / 25 / 91$ \\
\hline HNS IV & $\begin{array}{l}\text { Reacts down to minimum setting } \\
\text { on machine }-10 / 10 @ 0.5 \mathrm{~kg}\end{array}$ & $3 / 28 / 91$ \\
\hline HNX & $1 / 10 @ 16.0 \mathrm{~kg}$ & $8 / 12 / 91$ \\
\hline K-6 (scale-up batch) & $1 / 10 @ 6 / 2 \lg$ & $12 / 23 / 88$ \\
\hline LX-04-1 & $0 / 10 @ 36.0 \mathrm{~kg}$ & $9 / 11 / 92$ \\
\hline$L X-07-2$ & $0 / 10 @ 36.0 \mathrm{~kg}$ & $5 / 28 / 96$ \\
\hline$L X-10-2$ & $1 / 10 @ 16.4 \mathrm{~kg}$ & 9/11/92 \\
\hline$L X-11-0$ & $1 / 10 @ 32.4 \mathrm{~kg}$ & $2 / 8 / 95$ \\
\hline LX-14-0 & $1 / 10 @ 12.8 \mathrm{~kg}$ & $10 / 2 / 95$ \\
\hline$L X-16-0$ & $1 / 10 @ 10 / 2 \mathrm{~kg}$ & $1 / 22 / 96$ \\
\hline$L X-17-1$ & $0 / 10 @ 36.0 \mathrm{~kg}$ & $10 / 2 / 92$ \\
\hline Nitrocellulose (11\% nitration) & $1 / 10 @ 12.0 \mathrm{~kg}$ & $7 / 7 / 94$ \\
\hline PBX 9404 & $1 / 10 @ 18.0 \mathrm{~kg}$ & $2 / 23 / 94$ \\
\hline PETN & $1 / 10 @ 6.4 \mathrm{~kg}$ & $3 / 5 / 93$ \\
\hline $\mathrm{PZO}$ & $1 / 10 @ 8.4 \mathrm{~kg}$ & $2 / 26 / 92$ \\
\hline $\mathrm{RDX}$ & $1 / 10 @ 12.4 \mathrm{~kg}$ & $1 / 30 / 90$ \\
\hline TNAZ & $1 / 10 @ 11.6 \mathrm{~kg}$ & $4 / 21 / 94$ \\
\hline
\end{tabular}


* Glossary of Terms for Tables II \& III:

AHH Propellant Nitrocellulose (12.6\%) / Nitroglycerin / Triacetin /

2-Nitrodiphenylamine / Lead Salicylate / Lead-2-ethyl hexaoate (56.4/31.7/7.7/1.0/1.6/1.6)

ANFO

Ammonium nitrate-Fuel oil

ANTA

3-Amino-5-nitro-1,2,4-triazole

Black Powder

CEF

CL-14

Potassium Nitrate / Sulfur / charcoal (75/10/15)

tris- $\beta$-Chloroethylphosphate

CL-20 (epsilon)

5,7-Diamino-4,6-dinitrobenzofuroxan

Comp B-3

Hexanitrohexaazaisowurtzitane, or HNIW

2,4-DNI

RDX / TNT (59.5/40.5)

FEFO

2.4-Dinitroimidazole

Bis(fluorodinitroethyl)formal

HMX

HNS IV

Octahydro-1,3,5,7-tetranitro-1,3,5,7-tetrazocine

HNX

Hexanitrostilbene (polymorph IV)

4,6-Bis(5-amino-3-nitro-[1,2,4]-triazolyl)-5-nitropyrimidine

$\mathrm{K}-6$

$\mathrm{KP}$

Keto-RDX, or 2-Oxo-1,3,5-trinitrohexahydro-1,3,5-triazine

Potassium Perchlorate

LX-04-1

LX-07-2

HMX / Viton A binder (85/15)

$H M X /$ Viton $A$ binder (90/10)

$L X-10-2$

HMX / Viton A binder (94.5/5.5)

$L X-11-0$

HMX / Viton A binder (80/20)

$L X-14-0$

HMX / Estane 5702-F1 binder (95.5/4.5)

$L X-16-0$

LX-17-1

PETN / FPC-461 (or Exon 461, or Oxy 461) binder (96.5/3.5)

TATB / Kel-F 800 binder (92.5/7.5)

Nitrocellulose

PBX 9404

PETN

Gun Cotton (NC)

HMX / NC /CEF / Diphenylamine (94/3/3/1)

Pentaerythritol Tetranitrate

PZO

2,6-Diamino-3,5-dinitro-1,4-pyrazine-1-oxide

RDX

1,3,5-Trinitrohexahydro-1,3,5-triazine

TAG-ETNA

Triaminoguanidine Ethylenetetranitramine 


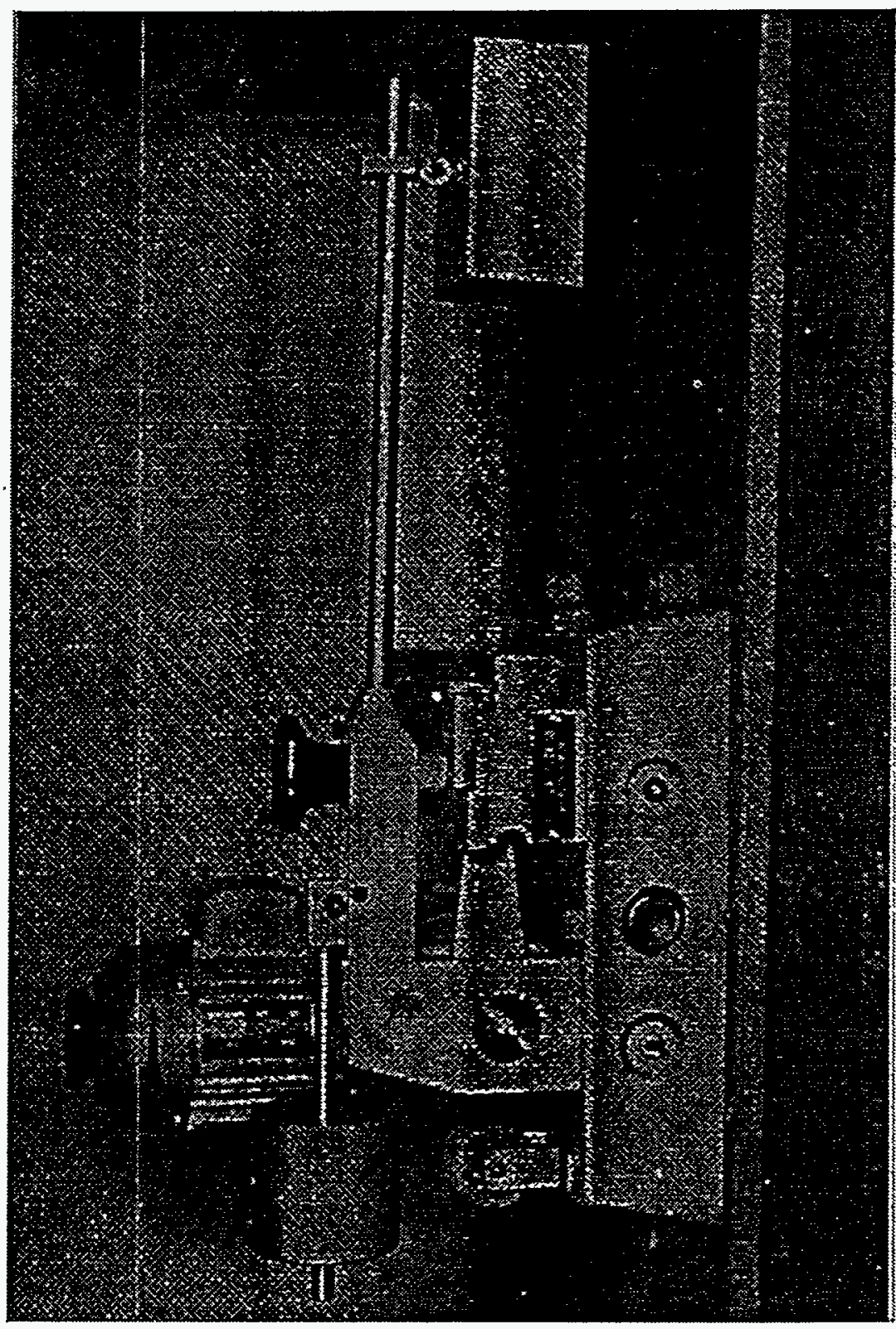

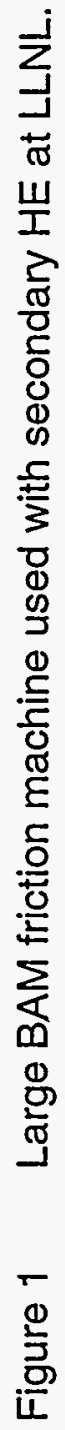

page 13 of 14 

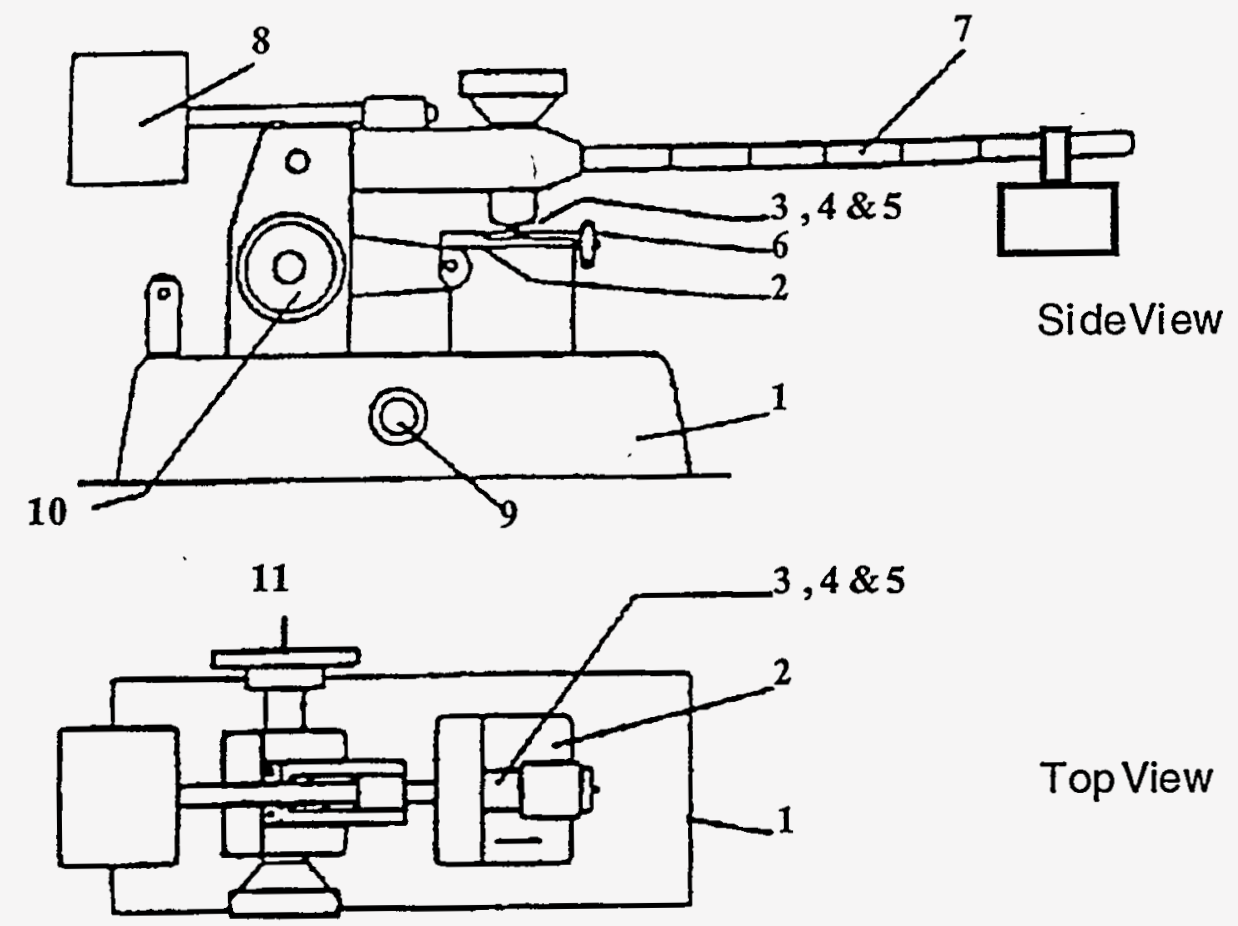

Figure 2 Side and vertical views of large BAM friction apparatus with load weight for determination of friction sensitivity of secondary explosives. Labelled are: 1) Steel base; 2) Movable carriage; 3) Porcelain plate clamped to carriage; 4) Fixed porcelain pin; 5) Sample on plate; 6) Adjusting rod; 7) Loading arm; 8) Counter weight; 9) Actuating switch; 10) Handle for setting the carriage at the starting position; 11) The electric motor drive (shown in Figure 1) attaches here.

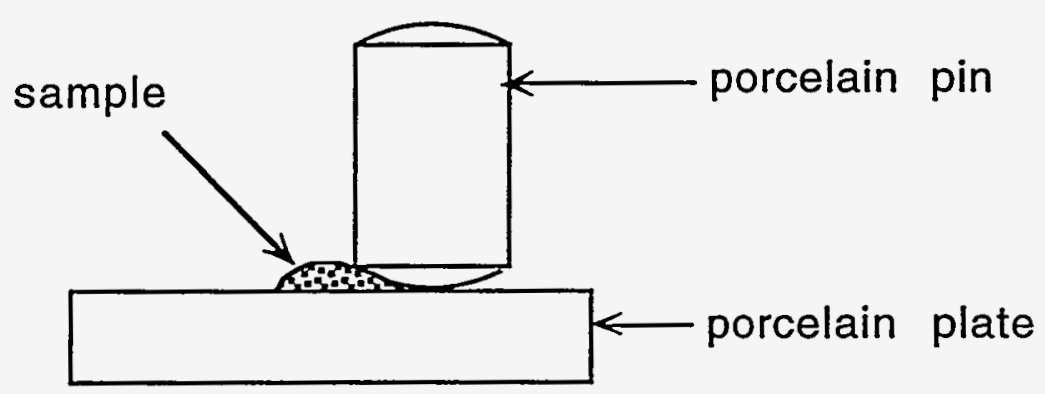

Figure 3 Starting position of pin, showing how the pin is set on the sample. 